\title{
Quebra de dormência de sementes de Delonix regia (Fabaceae)
}

\section{Overcome dormancy in seeds of Delonix regia (Fabaceae)}

\author{
Kássya Jemima Borges de Oliveira ${ }^{1}$ Jailma Suerda Silva de Lima¹, Lissa Izabel Ferreira \\ de Andrade 2 , Jacquelinne Alves de Medeiros Araújo Costa ${ }^{1 \star}$ e Joabe Freitas Crispim ${ }^{1}$
}

${ }^{1}$ Centro de Ciências Vegetais/Universidade Federal Rural do Semi-Árido, Mossoró-RN, Brasil, 59.625-9002

2 Departamento de Biologia/Universidade Federal de Lavras, Lavras-MG, Brasil, 37.200-000

(*E-mail: jacquelinne87@hotmail.com)

http://dx.doi.org/10.19084/RCA17302

Recebido/received: 2017.11.23

Recebido em versão revista/received in revised form: 2018.01.20

Aceite/accepted: 2017.01.23

\section{R E S U M O}

Objetivou-se avaliar métodos de quebra de dormência tegumentar em sementes de flamboyant. Conduzido em delineamento inteiramente casualizado com doze tratamentos e quatro repetições de 25 sementes, sendo: Testemunha (T1); Imersão em água, durante cinco minutos, a $100{ }^{\circ} \mathrm{C}$ (T2), $80{ }^{\circ} \mathrm{C}$ (T3) e $65{ }^{\circ} \mathrm{C}$ (T4); Imersão em ácido sulfúrico concentrado (97\%) durante cinco (T5) e dez minutos (T6); Escarificação mecânica (T7); Desponte na região oposta do embrião (T8); Corte do tegumento (T9); Imersão, durante quinze minutos, em vinagres de álcool (T10), vinho tinto (T11) e vinho branco (T12). Foram avaliados: porcentagens de germinação e de sementes duras e mortas, índice de velocidade de germinação, comprimento radicular, altura de plântula, número de folhas e massa seca das plântulas. Os maiores índices de velocidades de germinação foram proporcionados, respectivamente, pelo corte do tegumento, imersão em água a $100{ }^{\circ} \mathrm{C}$, escarificação mecânica e o desponte. Nenhum dos métodos de quebra de dormência utilizados apresentou efeito sobre a altura de plântulas, número de folhas e comprimento de raiz. Os tratamentos mais eficientes na quebra de dormência das sementes de flamboyant foram a imersão em água a $100{ }^{\circ} \mathrm{C}$, escarificação mecânica, desponte e o corte do tegumento.

Palavras-chave: flamboyant; dormência tegumentar; escarificação mecânica.

\begin{abstract}
A B S T R A C T
zhe study objective was to evaluate methods to overcome coat dormancy in flamboyant seeds. Conducted in a completely randomized design with twelve treatments and four replicates of 25 seeds, being: Witness (T1); Immersion in water for five minutes at $100{ }^{\circ} \mathrm{C}$ (T2), $80{ }^{\circ} \mathrm{C}$ (T3) and $65{ }^{\circ} \mathrm{C}$ (T4); Immersion in concentrated sulfuric acid (97\%) for five (T5) and ten minutes (T6); Mechanical scarification (T7); Stand in the opposite region of the embryo (T8); Cut of the integument (T9); Immersion for fifteen minutes in alcohol vinegars (T10), red wine (T11) and white wine (T12). The percentages of germination and hard and dead seeds, germination speed index, root length, seedling height, number of leaves and dry mass of the seedlings were evaluated. The highest rates of germination were provided, respectively, by tegument cutting, immersion in water at $100{ }^{\circ} \mathrm{C}$, mechanical scarification and peeling. None of the methods of breaking dormancy employed had any effect on seedling height, number of leaves and root length. The most efficient treatments in the dormancy breaking of flamboyant seeds were immersion in water at $100{ }^{\circ} \mathrm{C}$, mechanical scarification, peeling and tegument cutting.
\end{abstract}

Keywords: flamboyant; coat dormancy; mechanical scarification. 


\section{INTRODUÇÃO}

A maioria das espécies florestais apresentam dormência de sementes, fenómeno que apesar de ser fundamental na sobrevivência de muitas espécies, por permitir a distribuição da germinação ao longo do tempo, acaba limitando a produção de mudas (Fowler e Bianchetti, 2000; Brancalion et al., 2011; Melo et al., 2011; Rodrigues et al., 2012; Lima et al., 2013).

As sementes de flamboyant ou acácia-rubra (Delonix regia Bojer ex Hook.) Raf. (Fabaceae) apresentam dormência tegumentar, que compreende a impermeabilidade do tegumento à água e gases, como o oxigénio, promovendo uma resistência física ao crescimento do embrião, limitando, assim, a germinação (Zwirtes et al., 2013; Bertolini e Brun, 2014).

Diversos métodos podem ser utilizados para a quebra desse tipo de dormência como é o caso da escarificação mecânica, imersão da semente em água quente ou em água fria e a escarificação ácida, através da imersão em ácido sulfúrico (Fowler e Bianchetti, 2000; Azeredo et al., 2003).

Diversos trabalhos têm sido realizados sobre métodos de quebra da dormência tegumentar em sementes de espécies florestais, designadamente em Parkia platycephala Benth. (Nascimento et al., 2009), Piptadenia stipulacea (Benth.) Ducke (Farias et al., 2013), Piptadenia moniliformis Benth (Azeredo et al., 2010), além de flamboyant (Rodrigues et al., 2012; Lima et al., 2013; Bolognez et al., 2015; Câmara et al., 2015).

O uso da escarificação mecânica assim como a imersão de sementes de flamboyant em água aquecida a $100{ }^{\circ} \mathrm{C}$ proporcionaram maior percentagem de germinação de sementes de flamboyant em pesquisa realizada por Bolognez et al. (2015) evidenciando, assim, a eficiência da aplicação desses métodos de quebra em sementes de flamboyant já que quando não aplicados apenas um por cento das sementes germinaram.

Apesar das contribuições supracitadas, há a necessidade da realização de mais investigação visando avaliar o maior número possível de métodos de quebra de dormência para sementes de flamboyant e, dessa maneira, ampliar as informações referentes ao tema, facilitando a propagação da espécie. Perante o exposto, este trabalho teve como objetivo avaliar métodos de quebra de dormência tegumentar de sementes de flamboyant.

\section{MATERIAL E MÉTODOS}

O ensaio foi realizado em estufa do Departamento de Ciências Vegetais (DCV) da Universidade Federal Rural do Semi-Árido (UFERSA), Mossoró, RN (51 $11^{\prime}$ de latitude sul e $37^{\circ} 20^{\prime}$ de longitude W. Gr.), no período de maio a junho de 2013. Para isso, utilizaram-se sementes de flamboyant, colhidas manualmente de árvores localizadas no campus central da UFERSA.

O delineamento experimental utilizado foi o inteiramente casualizado, com doze tratamentos e quatro repetições de 25 sementes. As sementes foram submetidas aos seguintes tratamentos: Testemunha - sementes intactas (T1); Imersão durante cinco minutos em água a $100^{\circ} \mathrm{C}(\mathrm{T} 2)$, a $80^{\circ} \mathrm{C}$ (T3) e a $65{ }^{\circ} \mathrm{C}$ (T4); Imersão em ácido sulfúrico concentrado (97\%) durante cinco minutos (T5), e durante dez minutos (T6); Escarificação em lixa número 120 (T7); Desponte na região oposta do embrião (T8); Corte do tegumento na extremidade do ponto de inserção da vagem (T9); Imersão em vinagre de álcool durante quinze minutos (T10); Imersão em vinagre de vinho tinto durante quinze minutos (T11); Imersão em vinagre de vinho branco durante quinze minutos (T12). Após serem submetidas aos tratamentos, as sementes foram semeadas em bandejas plásticas, com dimensões $33 \times 23 \times 45 \mathrm{~cm}$ (comprimento, largura e altura), previamente lavadas e esterilizadas com lexívia a $10 \%$ durante cinco minutos. O substrato utilizado foi a areia lavada e esterilizada em autoclave a $121^{\circ} \mathrm{C}$ durante 60 minutos. O ensaio foi conduzido em estufa sob sombra e temperatura ambiente média de $35^{\circ} \mathrm{C}$. Durante a condução do ensaio foram realizadas regas diárias para manter a umidade adequada à germinação das sementes e as bandejas foram remanejadas para evitar o efeito local.

As avaliações consistiram das seguintes variáveis: porcentagem de germinação; porcentagem de sementes duras e mortas; índice de velocidade de germinação (IVG); comprimento radicular; altura 
de plântula; número de folhas; e massa seca das plântulas. $\mathrm{O}$ índice de velocidade de germinação (IVG) foi obtido através de contagens diárias, conforme proposto por Maguire (1962). No final do teste de germinação, foi retirada uma amostragem de 10 plântulas normais das plântulas centrais de cada repetição para obtenção das características altura de plântulas e comprimento de raiz - as quais foram medidas com o auxilio de uma régua graduada em centímetros, sendo os resultados expressos em centímetros. O número de folhas foi obtido pela contagem direta e a massa seca das plântulas, a partir da secagem das mesmas em estufa à $60^{\circ} \mathrm{C}$ até obter peso constante, e em seguida, pesadas em balança analítica.

Os dados obtidos foram submetidos à análise de variância utilizando o programa estatístico SISVAR (Ferreira, 2003) e, quando os valores de " $F$ " foram significativos, as médias foram contrastadas pelo teste de Tukey ao nível de 5\% de probabilidade.

\section{RESULTADOS E DISCUSSÃO}

A imersão em água a $100{ }^{\circ} \mathrm{C}$ durante cinco minutos (T2), a escarificação mecânica (T3), o desponte da região oposta ao embrião (T8) e o corte do tegumento próximo à região de inserção na vagem (T9), foram os tratamentos que proporcionaram maior percentagem de germinação das sementes de flamboyant, bem como maiores IVG e menores percentuais de sementes duras, sendo, portanto, os mais eficientes na quebra da dormência dessas sementes. Os tratamentos imersão em água a $65^{\circ} \mathrm{C}$ durante cinco minutos (T4), em ácido sulfúrico concentrado durante cinco (T5) e dez minutos (T6), em vinagre de álcool (T10), em vinagre de vinho tinto (T11) e em vinagre de vinho branco (T12), durante quinze minutos, não tiveram efeito sobre a germinação das sementes, uma vez que não diferiram estatisticamente da testemunha quanto a percentagem de germinação e de sementes duras (Figura 1).

A imersão em água a $100{ }^{\circ} \mathrm{C}$ durante cinco minutos mostrou-se eficiente na quebra da dormência em sementes de flamboyant, proporcionando um IVG de 37, todavia provocou uma percentagem de mortalidade das sementes de 29\%. Resultado semelhante ao obtido por Ataíde et al. (2013) que concluíram que a imersão das sementes de flamboyant em água quente $\left(90^{\circ} \mathrm{C}\right)$ durante um minuto apesar de ter proporcionado maior IVG causou uma percentagem de sementes mortas de $16 \%$. Bolognez et al. (2015) também verificaram que apesar da imersão das sementes de flamboyant em água quente $\left(90^{\circ} \mathrm{C}\right.$ ) promover maior percentagem de germinação (77\%) proporcionou maior percentagem de sementes mortas (7\%).

A percentagem de sementes mortas obtida com a aplicação desse tratamento pode estar associado ao fato da temperatura elevada da água em que as sementes foram submetidas, ter ocasionado danos no embrião e, consequentemente, a morte das sementes (Bruno et al., 2001; Silva et al., 2011).

A imersão em água quente consiste num método barato, segundo Piroli et al. (2005), e que pode ser usada em larga escala, podendo ser utilizada como técnica de quebra de dormência em sementes, pois promove o amolecimento dos tecidos, favorecendo a absorção de água, além de trocas gasosas e, consequente germinação das sementes (Martins et al., 1997).

A escarificação mecânica, através do uso da lixa $\mathrm{n}^{\circ}$ 120, proporcionou elevada percentagem de germinação (72\%) e elevado IVG (39) das sementes de flamboyant. Lima et al. (2013) e Zwirtes et al. (2013) constataram que a escarificação mecânica em sementes de flamboyant foi o método que proporcionou maior IVG. A eficiência da escarificação mecânica pode estar associada ao fato da mesma promover fissuras no tegumento, aumentando a permeabilidade das sementes e permitir, assim, a embebição e consequente germinação (Franke e Baseggio, 1998; Medeiros Filho et al., 2002; Zwirtes et al., 2013). A escarificação mecânica, segundo Santos et al. (2004), compreende uma técnica simples e de baixo custo, que apresenta alta eficiência na quebra de dormência tegumentar, promovendo uma rápida e uniforme germinação das sementes. A eficiência dessa técnica também tem sido relatada noutras espécies florestais, como Bauhinia divaricata L. (Alves et al., 2004), Parkia spp. (Melo et al., 2011), Sesbania virgata (Cav.) Pers. (Silva et al., 2011), Sterculia foetida L. (Santos et al., 2004). A escarificação mecânica, apesar de ser eficiente na quebra de dormência, pode acarretar altas taxas de sementes mortas, fato constatado no presente trabalho, em que houve uma percentagem de 


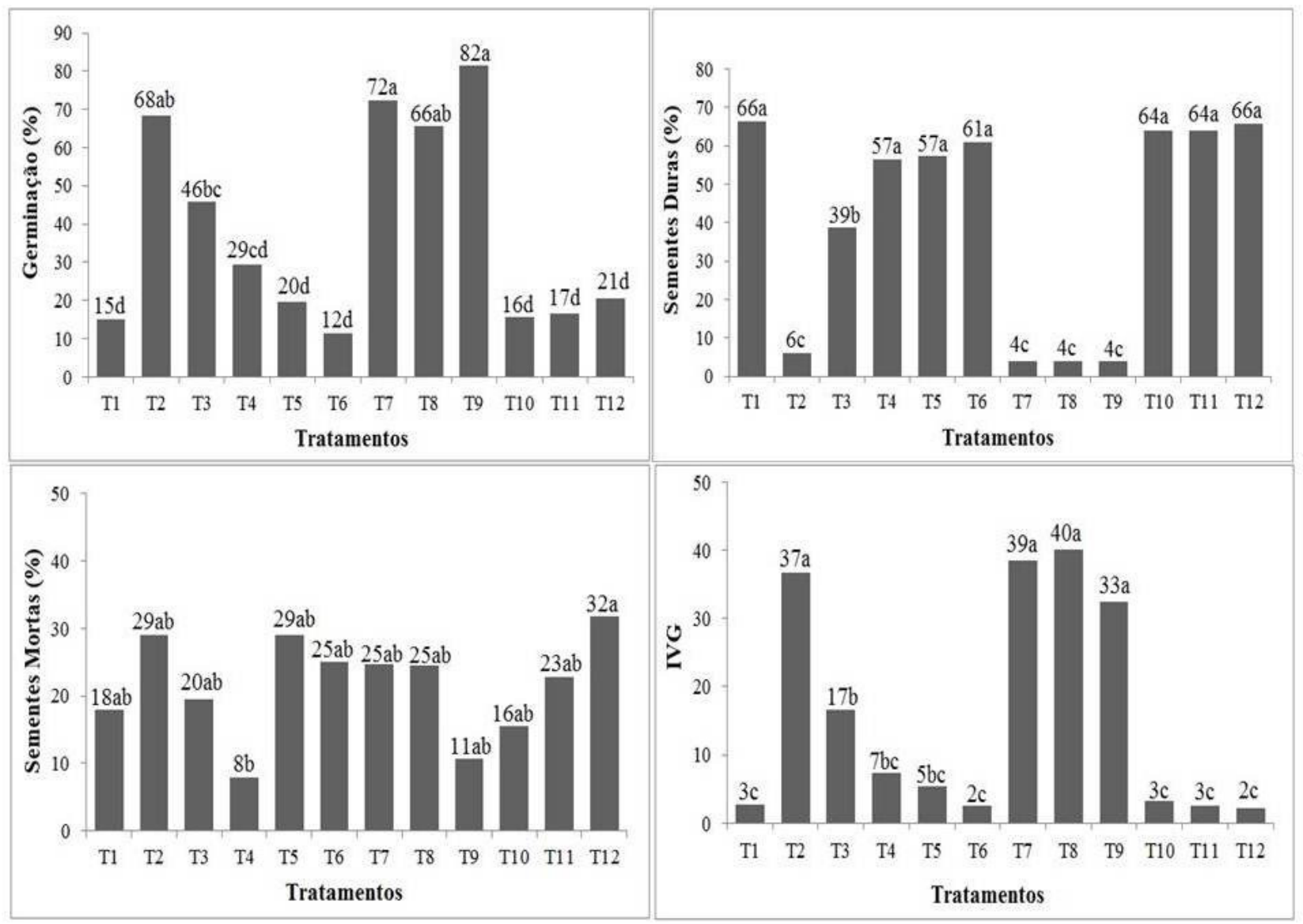

Figura 1 - Médias da porcentagem de germinação (A), porcentagem de sementes duras (B), porcentagem de sementes mortas (C) e IVG (D) de sementes de flamboyant (Delonix regia (Bojer ex Hook.) Raf.) sob diferentes métodos de quebra de dormência.

*Médias seguidas pela mesma letra minúscula não diferem entre si pelo teste de Tukey ao nível de $5 \%$ de probabilidade. T1 - testemunha (sementes intactas); T2 imersão em água a $100{ }^{\circ} \mathrm{C}$ por cinco minutos; T3 - imersão em água a $80^{\circ} \mathrm{C}$ por cinco minutos; T4 - imersão em água a $65^{\circ} \mathrm{C}$ por cinco minutos; T5 - imersão em ácido sulfúrico concentrado por 5 minutos; T6 - imersão em ácido sulfúrico concentrado por 10 minutos; T7 - escarificação em lixa número 120; T8 - desponte na região oposta do embrião; T9 - corte do tegumento na extremidade do ponto de inserção da vagem; T10 - imersão em vinagre de álcool por 15 minutos; T11 - imersão em vinagre de vinho tinto por 15 minutos; e T12 - imersão em vinagre de vinho branco por 15 minutos. IVG - índice de velocidade de germinação.

$24,75 \%$ quando aplicado esse tratamento. Resultado semelhante ao obtido por Medeiros Filho et al. (2002) com sementes de Operculina macrocarpa (L.) Farwel com a realização da escarificação mecânica, o que pode estar associada a danos causados no embrião através da realização dessa técnica (Franke e Baseggio, 1998).

A imersão em ácido sulfúrico concentrado, durante cinco e dez minutos, não mostrou nenhum efeito sobre a germinação das sementes, uma vez que apresentaram estatisticamente a percentagem de germinação da testemunha, além de ter promovido uma percentagem de sementes mortas de, respectivamente $29 \%$ e $25 \%$, valores superiores aos observados na testemunha. Resultado semelhantes foram obtidos por Ataíde et al. (2013), em que os tratamentos com ácido sulfúrico não foram eficientes na quebra da dormência de sementes de flamboyant, uma vez que nesses tratamentos, foi observada maior porcentagem de sementes duras no final do teste de germinação.

A baixa eficiência da escarificação ácida através da imersão em ácido sulfúrico pode, segundo Zwirtes et al. (2013), estar associada ao tempo de imersão das sementes, que pode ter sido insuficiente para a quebra da dormência, ou ainda, à concentração do ácido sulfúrico, que segundo Missio et al. (2011), é importante na quebra da dormência, uma vez que 
altas concentrações desse ácido podem ocasionar danos às células embrionárias, promovendo alto percentagem de sementes mortas.

A imersão em ácido sulfúrico durante 30 minutos proporcionou elevado percentagem de germinação (60\%) em sementes de Sesbania virgata (Cav.) Pers., em estudos realizados por Silva et al. (2011), enquanto que quando realizada a imersão durante 5 e 10 minutos verificaram os menores valores de germinação. Em sementes de Parkia velutina Benoist e Parkia panurensis H.C. Hopkins a escarificação química com ácido sulfúrico em maior tempo de imersão (30 minutos) foi mais eficiente tanto para a emergência de plântulas quanto para formação de plântulas normais quando comparada com a imersão em ácido sulfúrico por 15 e 20 minutos (Melo et al., 2011), enquanto que a imersão de sementes de acácia (Acacia mangium Willd.) em ácido sulfúrico por 90 minutos apresentou maior valor de vigor, sendo considerado método eficiente de quebra de dormência nessa espécie florestal (Rodrigues et al., 2008).

Os resultados indicaram ainda efeito significativo do desponte da região oposta ao embrião e do corte do tegumento próximo à região de inserção na vagem sobre a quebra da quebra de dormência das sementes de flamboyant. A eficiência do método de desponte sobre a quebra de dormência de sementes, também tem sido relatada em diversas espécies florestais, como em Adenanthera pavonina L. (Silva et al., 2009), Delonix regia Rafin (Rodrigues et al., 2012), Mimosa caesalpiniaefolia Benth. (Bruno et al., 2001), Bauhinia divaricata L. (Alves et al., 2004), Parkia discolor Spruce ex. Benth. (Pereira e Ferreira, 2010), Piptadenia stipulacea (Benth.) Ducke (Farias et al., 2013). Rodrigues et al. (2012), observaram que o desponte com auxílio de tesoura, por meio de pequeno corte na região oposta ao hilo, não diferiu estatisticamente do método da imersão das sementes de flamboyant em água à temperatura de $35^{\circ} \mathrm{C}$, com posterior repouso na mesma água (fora do aquecimento) por 24 horas e, sendo estas as técnicas mais eficientes na quebra da dormência.

Os tratamentos referentes à imersão de sementes de flamboyant em vinagre de álcool (T10), em vinagre de vinho tinto (T11) e em vinagre de vinho branco (T12) durante quinze minutos, não apresentaram nenhum efeito sobre a germinação das sementes, uma vez que não diferiram estatisticamente da testemunha. Nietsche et al. (2005), também não verificaram nenhum efeito significativo da imersão em vinagre, das sementes de pinheira (Annona squamosa L.), em relação à quebra da dormência dessas sementes. Já Câmara et al. (2008), verificaram que a imersão de sementes de jucá (Caesalpinia ferrea Mart. ex.Tul.) em vinagre de vinho branco favoreceu a germinação, o índice de velocidade de germinação, e o acúmulo de matéria fresca e seca de plântulas de jucá, embora a imersão das sementes de jucá em vinagre de álcool e em vinagre de vinho tinto não terem sido eficientes na quebra da dormência dessas sementes.

Em relação à ação dos métodos de quebra de dormência empregados sobre a altura de plântulas, número de folhas e comprimento de raiz, os resultados não indicaram nenhum efeito significativo sobre os mesmos. A imersão em água a $100{ }^{\circ} \mathrm{C}$ durante cinco minutos (T2), a imersão em água a $80{ }^{\circ} \mathrm{C}$ por cinco minutos (T3), o desponte na região oposta do embrião (T8) e o corte do tegumento na extremidade do ponto de inserção da vagem (T9), foram os métodos que proporcionaram maiores teores de matéria seca, não diferindo estatisticamente entre si (Figura 2).

Os resultados não indicaram efeito significativo de nenhum dos métodos de quebra de dormência empregados em relação à altura de plântulas, número de folhas e comprimento de raiz, resultados divergentes ao obtidos por Lima et al. (2013), que verificaram que a imersão das sementes de flamboyant em água a $80{ }^{\circ} \mathrm{C}$ durante cinco minutos promoveu maior altura de plântulas $(8,55 \mathrm{~cm})$, e a escarificação mecânica em lixa durante cinco minutos, maior crescimento da raiz $(4,96 \mathrm{~cm})$. Roversi et al. (2002), verificaram que, sob condições de viveiro aos dois meses após a sementeira, não houve diferenças estatísticas significativas entre os tratamentos, exceto para a testemunha, sobre o crescimento radicular e o comprimento da parte aérea de Acacia mearnsii Willd..

Em relação aos teores de matéria seca (Figura 2D) pode-se observar que os maiores teores foram obtidos através da imersão das sementes de flamboyant em água a $100{ }^{\circ} \mathrm{C}$ durante cinco minutos (T2), imersão em água a $80^{\circ} \mathrm{C}$ durante cinco minutos (T3), o desponte na região oposta do embrião (T8) e 


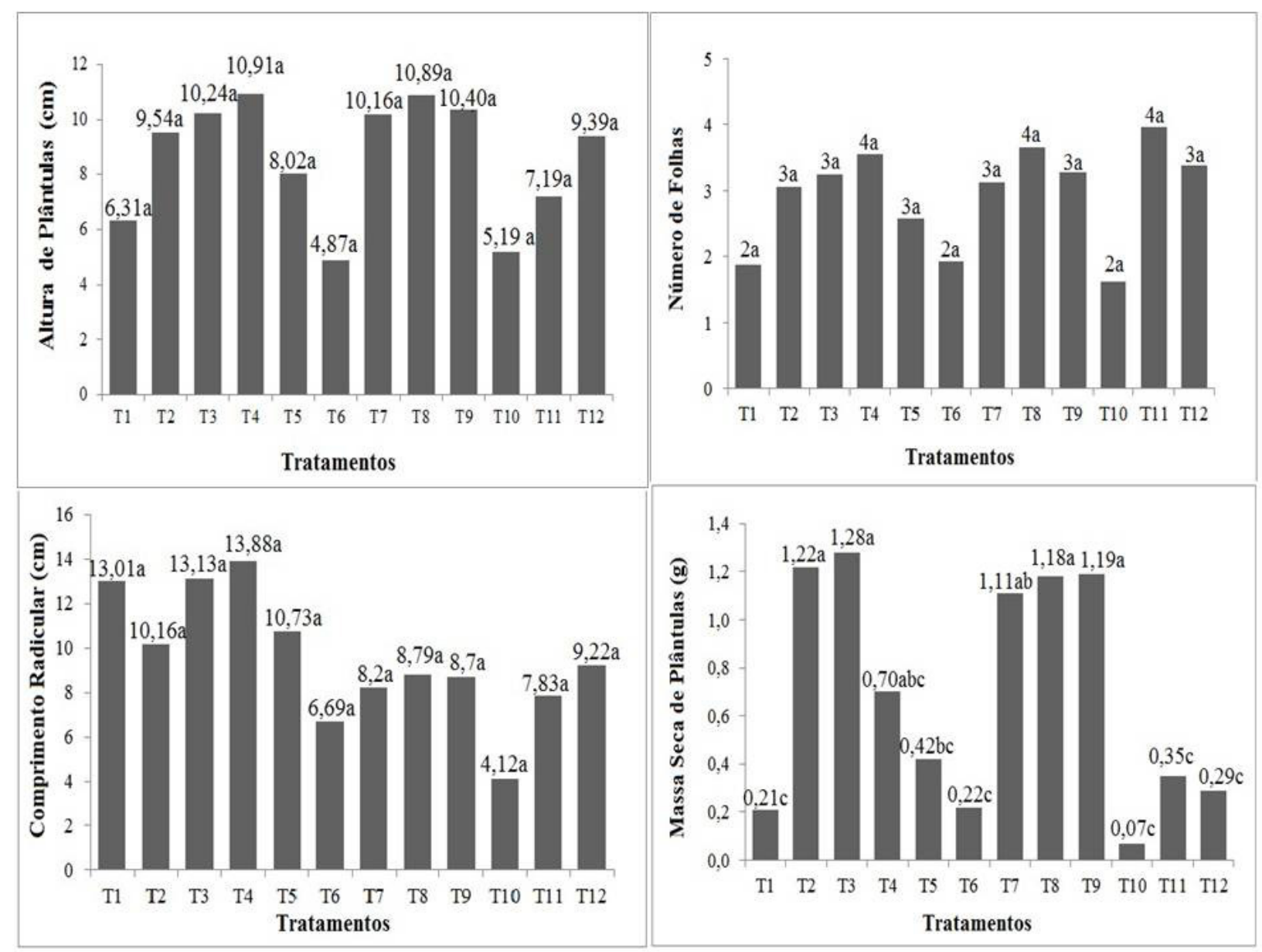

Figura 2 - Médias de altura de plântulas (A), número de folhas (B), comprimento radicular (C) e massa seca de plântulas (D) de sementes de flamboyant (Delonix regia (Bojer ex Hook.) Raf.) sob diferentes métodos de superação de dormência.

*Médias seguidas pela mesma letra minúscula não diferem entre si pelo teste de Tukey ao nível de $5 \%$ de probabilidade. T1 - testemunha (sementes intactas); T2 imersão em água a $100^{\circ} \mathrm{C}$ por cinco minutos; T3 - imersão em água a $80^{\circ} \mathrm{C}$ por cinco minutos; $\mathrm{T} 4$ - imersão em água a $65^{\circ} \mathrm{C}$ por cinco minutos; T5 - imersão em ácido sulfúrico concentrado por 5 minutos; T6 - imersão em ácido sulfúrico concentrado por 10 minutos; T7 - escarificação em lixa número 120; T8 - desponte na região oposta do embrião; T9 - corte do tegumento na extremidade do ponto de inserção da vagem; T10 - imersão em vinagre de álcool por 15 minutos; T11 - imersão em vinagre de vinho tinto por 15 minutos; e T12 - imersão em vinagre de vinho branco por 15 minutos.

o corte do tegumento na extremidade do ponto de inserção da vagem (T9), os quais proporcionaram respectivamente, 1,22 g, 1,28 g, 1,18 g, 1,19 g, não diferindo estatisticamente entre si. Resultados semelhantes foram obtidos por Alves et al. (2004), em que os maiores valores da matéria seca de plântulas de Bauhinia divaricata L. foram obtidos através do desponte na região oposta ao micrópilo, da imersão em água a temperatura de $70^{\circ} \mathrm{C}$, e imersão em água a $60^{\circ} \mathrm{C}$, os quais não diferiram estatisticamente entre si.

A ação de métodos de quebra de dormência de sementes sobre a matéria seca de plântulas, também tem sido relatada sobre outras espécies florestais, como por exemplo, Mimosa caesalpiniaefolia Benth. (sabiá), em que a escarificação ácida e o desponte foram os métodos que proporcionaram melhores resultados de matéria seca, enquanto que a imersão em água quente proporcionou menor conteúdo de matéria seca das plântulas (Bruno et al., 2001). Santos et al. (2004) verificaram que a escarificação em um lado com embebição por 24 h, proporcionou maior teor de matéria seca da parte aérea de plântulas de Sterculia foetida L., enquanto que a matéria seca do sistema radicular não foi afetada pelos tratamentos aplicados, já que não diferiram estatisticamente entre si, inclusive entre 
a testemunha. Rebouças et al. (2012), concluíram que os maiores teores de matéria seca da raiz e matéria seca da parte aérea foram obtidos quando as sementes de quixabeira (S. obtusifolium) foram submetidas a escarificação química com ácido sulfúrico durante 20 e 30 minutos.

\section{CONCLUSÃO}

A imersão em água a $100{ }^{\circ} \mathrm{C}$ durante cinco minutos, a escarificação mecânica com lixa número 120, o desponte da região oposta ao embrião e o corte do tegumento próximo à região de inserção da vagem foram os tratamentos mais eficientes na quebra de dormência em sementes de flamboyant.

\section{REFERÊNCIAS BIBLIOGRÁFICAS}

Alves, A.U.; Dornelas, C.S.M.; Bruno, R.L.A. \& Andrade, L.A. \& Alves, E. U. (2004) - Superação da dormência em sementes de Bauhinia divaricata L. Acta Botânica Brasileira, vol. 18, n. 4, p. 871-879. http://dx.doi.org/10.1590/ S0102-33062004000400018

Ataíde, G.M.; Bicalho, E.M.; Dias, D.C.F.S.; Castro, R.V.O. \& Alvarenga, E.M. (2013) - Superação da dormência das sementes de Delonix regia (Bojer ex Hook.) Raf. Revista Árvore, vol. 37, n. 6, p. 1145-1152. http://dx.doi. org/10.1590/S0100-67622013000600016

Azeredo, G.A.; Bruno, R.L.A.; Andrade, L. A. \& Cunha, A.O. (2003) - Germinação em sementes de espécies floresta da Mata Atlântica (Leguminoseae) sob condições de casa de vegetação. Pesquisa Agropecuária Tropical, vol. 33, n. 1, p. 11-16.

Azeredo, G.A.; Paula, R.C.; Valeri, S.V. \& Moro, F.V. (2010) - Superação de dormência de sementes de Piptadenia moniliformis Benth. Revista Brasileira de Sementes, vol. 32, n. 2, p. 49-58. http://dx.doi.org/10.1590/ S0101-31222010000200006

Bertolini, I.C. \& Brun, E.J. (2014) - A influência do método de semeadura no crescimento de mudas de flamboyant (Delonix regia (Bojer ex Hook) Raf.) em viveiro florestal. Revista da Sociedade Brasileira de Arborização Urbana, vol. 9, n. 4, p. 181-198.

Bolognez, C.A.; Pohl, S.; Meneguello, G.E.; Medeiros, M.O. \& Amaral, J.L. (2015) - Superação de dormência em sementes de flamboyant (Delonix regia (Bojer ex Hook) Raf.). Enciclopédia Biosfera, vol. 11, n. 22, p. 25682575. http://dx.doi.org/10.18677/Enciclopedia_Biosfera_2015_226

Brancalion, P.H.S.; Mondo, V.H.V. \& Novembre, A.D.L.C. (2011) - Escarificação química para a Superação da dormência de sementes de saguaraji-vermelho (Colubrina glandulosa Perk. - Rhamnaceae). Revista Árvore, vol. 35, n. 1, p. 119-124. http://dx.doi.org/10.1590/S0100-67622011000100014

Bruno, R.L.A.; Alves, E.U.; Oliveira, A.P. \& Paula, R.C. (2001) - Tratamentos pré-germinativos para superar a dormência de sementes de Mimosa caesalpiniaefolia Benth. Revista Brasileira de Sementes, vol. 33, n. 2, p. 136-143. http://dx.doi.org/10.17801/0101-3122/rbs.v23n2p136-143

Câmara, F.A.A.; Torres, S.B.; Guimarães, I.P.; Oliveira, M.K.T. \& Oliveira, F.A. (2008) - Biometria de frutos e sementes e Superação de dormência de jucá (Caesalpinia ferrea Mart. Ex. Tul (Leguminosae Caesalpinoideae)). Revista Caatinga, vol. 21, n. 4, p. 172-178.

Câmara, F.M.M.; Pereira, E.C.; Carneiro, J.V.; Oliveira, H.T.B.; Silva, R.M. \& Pereira, G.A. (2015) - Métodos alternativos na Superação de dormência em sementes de flamboyant. Agropecuária Científica no Semiárido, vol. 11, n. 3, p. 76-83.

Farias, R.M.; Freitas, R.M.O.; Nogueira, N.W. \& Dombroski, J.L.D. (2013) - Superação de dormência em sementes de jurema-branca (Piptadenia stipulacea). Amazonian Journal of Agricultural and Environmental Sciences, vol. 56, n. 2, p. 160-165. http://dx.doi.org/10.4322/rca.2013.024

Ferreira, D.S. (2003) - SISVAR versão 4.3 (Build 45). Lavras: DEX/UFLA.

Fowler, J.A.P. \& Bianchetti, A. (2000) - Dormência em sementes florestais. Colombo: Embrapa Florestas, Documentos 40, 27 p.

Franke, L.B. \& Baseggio, J. (1998) - Superação da dormência de sementes de Desmodium incanum DC. e Lathyrus nervosus Lam. Revista Brasileira de Sementes, vol. 20, n. 2, p. 182-186. http://dx.doi.org/10.17801/01013122/rbs.v20n2p182-186 
Lima, J.S.; Chaves, A.P.; Medeiros, M.A.; Rodrigues, G.S.O. \& Benedito, C.P. (2013) - Métodos de Superação de dormência em sementes de flamboyant (Delonix regia). Revista Verde de Agroecologia e Desenvolvimento Sustentável, vol. 8, n. 1, p. 104-109,

Maguire, J.D. (1962) - Speed of germination-aid in selection and evaluation for seedling emergence and vigor. Crop Science, vol. 2, n. 1, p. 176-177. http://dx.doi.org/10.2135/cropsci1962.0011183X000200020033x

Martins, C.C.; Mendonça, C.G.; Martins, D. \& Velini, E.D. (1997) - Superação de dormência de sementes de carrapicho-beiço-de-boi. Revista Planta Daninha, vol. 15, n. 2, p. 104-113. http://dx.doi.org/10.1590/5010083581997000200003

Medeiros Filho, S.; França, E.A. \& Innecco, R. (2002) - Germinação de sementes de Operculina macrocarpa (L.) Farwel e Operculina alata (Ham.) Urban. Revista Brasileira de Sementes, vol. 24, n. 2, p. 102-107. http://dx.doi. org/10.1590/S0101-31222002000100017

Melo, M.G.G.; Mendonça, M.S.; Nazário, P. \& Mendes, A.M.S. (2011) - Superação de dormência em sementes de três espécies de Parkia spp. Revista Brasileira de Sementes, vol. 33, n. 3, p. 533-542. http://dx.doi.org/10.1590/ S0101-31222011000300016

Missio, E.L.; Maurmann, R.; Trevian, R. \& Trento, R. (2011) - Resposta de sementes de flamboyant submetidas a dois métodos de Superação de dormência. Revista da FZVA, vol. 18, n. 2, p. 46-55.

Nascimento, I.L.; Alves, E.U.; Bruno, R.L.A.; Gonçalves, E.P.; Colares, P.N.Q. \& Medeiros, M.S. (2009) Superação da dormência em sementes de faveira (Parkia platycephala Benth). Revista Árvore, vol. 33, n. 1, p. 35-45. http://dx.doi.org/10.1590/S0100-67622009000100005

Nietsche, S.; Pereira, M.C.T.; Nunes, C.F.; Cunha, L.M.V.; Gonçalves, V.D.; Mota, W.F. \& Santos, F.A. (2005) - Tratamentos físicos e químicos na emergência e no crescimento de plântulas de pinheira. Bragantia, vol. 64, n. 3, p. 411-416. http://dx.doi.org/10.1590/S0006-87052005000300010

Pereira, S.A. \& Ferreira, S.A.N. (2010) - Superação da dormência em sementes de visqueiro-do-igapó (Parkia discolor). Acta Amazônica, vol. 40, n. 1, p. 151-156. http://dx.doi.org/10.1590/S0044-59672010000100019

Piroli, E.L.; Custódio, C.C.; Rocha, M.R.V. \& Udenal, J.L. (2005) - Germinação de sementes de canafístula Peltophorum dubium (Spreng.) Taub. tratadas para Superação da dormência. Colloquium Agrariae, vol. 1, n. 1, p. 13-18.

Rebouças, A.C.M.N.; Matos, V.P.; Ferreira, R.L.C.; Sena, L.H.M.; Sales, A.G.F.A. \& Ferreira, E.G.B.S. (2012) - Métodos de Superação da dormência de sementes de quixabeira (Sideroxylon obtusifolium (Roem. \& Schult.) T. D. Penn.). Ciência Florestal, vol. 22, n. 1, p. 183-192. http://dx.doi.org/10.5902/198050985090

Rodrigues, A.P.D.; Kohl, M.C.; Pedrinho, D.R. \& Arias, E.R.A.; Favero, S. (2008) - Tratamentos para superar a dormência de sementes de Acacia mangium Willd. Acta Scientiarum Agronomy, vol. 30, n. 2, p. 279-283. http://dx.doi.org/10.4025/actasciagron.v30i2.1786

Rodrigues, P.S.; Moreira, A.L.C. \& Martins, R.C.C. (2012) - Avaliação de métodos para quebra da dormência e caracterização morfológica de sementes de Delonix regia Rafin (Fabaceae). Candombá - Revista Virtual, vol. 8, n. 1, p. 81-90.

Roversi, T.; Mattei, V.L.; Silveira Júnior, p. \& Falck, G.L. (2002) - Superação da dormência em sementes de acácia negra (Acacia mearnsii Willd.). Revista Brasileira de Agrociência, vol. 8, n. 2, p. 161-163.

Santos, T.O.; Morais, T.G.O. \& Matos, V.P. (2004) - Escarificação mecânica em sementes de Chichá (Sterculia foetida L.). Revista Árvore, vol. 28, n. 1, p. 1-6. http://dx.doi.org/10.1590/S0100-67622004000100001

Silva, A.I.S.; Corte, V.B.; Pereira, M.D.; Cuzzuol, G.R.F. \& Leite, I.T.A. (2009) - Efeito da temperatura e de tratamentos pré-germinativos na germinação de sementes de Adenanthera pavonina L. Semina: Ciências Agrárias, vol. 30, n. 4, p. 815-824. http://dx.doi.org/10.5433/1679-0359.2009v30n4p815

Silva, P.E.M.; Santiago, E.F.; Daloso, D.M.; Silva, E.M. \& Silva, J.O. (2011) - Quebra de dormência em sementes de Sesbania virgata (Cav.) Pers. IDESIA, vol. 29, n. 2, p. 39-45. http://dx.doi.org/10.4067/S0718-34292011000200005

Zwirtes, A.L.; Baronio, C.A.; Cantarelli, E.B.; Rigon, J.P.G. \& Capuani, S. (2013) - Métodos de Superação de dormência em sementes de flamboyant. Pesquisa Florestal Brasileira, vol. 33, n. 76, p. 469-473. http://dx.doi. org/10.4336/2013.pfb.33.76.568 